\title{
Synthesis of Triazoles by Electro-Assisted Click Reaction Using a Copper Foil Electrode
}

\author{
Luceldi Carre-Rangel, ${ }^{a}$ Karla A. Espinoza, ${ }^{a}$ Mercedes T. Oropeza-Guzmán ${ }^{a}$ and \\ Ignacio A. Rivero ${ }^{\circledR *} * a$
}

\author{
${ }^{a}$ Centro de Graduados e Investigación en Química, Tecnológico Nacional de México, \\ Instituto Tecnológico de Tijuana, C.P. 22500 Tijuana, B. C., México
}

\begin{abstract}
This paper presents an innovative pathway for the synthesis of triazoles using the well-known "click chemistry" assisted by the electrochemical oxidation of metallic $\mathrm{Cu}^{0}$. The click reaction is used to couple a wide range of biological interest compounds. In this case, faster and less polluting methods for a biological environment was achived by in situ $\mathrm{Cu}^{0}$ electrooxidation, providing the suitable quantity of catalyst required by click reaction. The electrochemical cell was composed of a copper foil as the working electrode, a platinum wire serving as a counter electrode, and an $\mathrm{Ag} / \mathrm{AgCl}$ wire as the reference electrode. Linear anodic sweep voltammetry in a tert-butanol-water medium (1:1), an electrolyte of tetrabutylammonium tetrafluoroborate (TBATFB), showed the onset potential of $\mathrm{Cu}^{0}$ electrooxidation. Using the same electrode configuration three different triazoles were prepared under constant electrode potential, in a short time $(60 \mathrm{~min})$, and splendid yields (78-90\%). These results indicate that the in situ $\mathrm{Cu}^{\mathrm{I}}$ formation occurs on the surface of the copper foil. A pulse potential program has also been implemented in which a yield of $92 \%$ was achieved, reducing electrode passivation and consequently increasing the process efficiency. The electroassisted click reactions are highly efficient to produce triazoles by an innovative electrochemical reaction. The products were characterized by infrared (IR), nuclear magnetic resonance $\left({ }^{1} \mathrm{H}\right.$ and ${ }^{13} \mathrm{C} \mathrm{NMR}$ ), and mass spectrometry (MS).
\end{abstract}

Keywords: click reaction, azide, triazole, $\mathrm{Cu}$ electrooxidation, organic electrosynthesis

\section{Introduction}

The click chemistry is a green, selective, qualitative, $\mathrm{pH}$-sensitive, and economical affordable,$^{1}$ suitable for the synthesis of a variety of bioconjugates including peptides, ${ }^{2}$ proteins, ${ }^{3}$ and polysaccharides, ${ }^{4}$ among others.

The purpose of the click chemistry is to selectively bind two molecular building blocks, under mild reaction conditions, obtaining high yields and harmless byproducts. Another characteristic is the easy way to separate main products by non-chromatographic methods. ${ }^{5}$ Some examples of reactions that fall into the category of click reactions are the synthesis of thiolene, ${ }^{6}$ oximes, ${ }^{7}$ Diels-Alder reactions, ${ }^{8}$ Michael addition, ${ }^{9}$ etc., however, the most known is the $\mathrm{Cu}^{\mathrm{I}}$-catalyzed azidealkyne click cycloaddition (CuAAC).${ }^{10}$ The CuAAC has become one of the most used models due to its wide field of application, its easy scale-up, and its high reaction

*e-mail: irivero@tectijuana.mx yield. Another important point is that it is not affected by the presence of functional groups and can proceed with various sources of $\mathrm{Cu}^{\mathrm{I}} .^{10-12}$

Thus, the click chemistry has increased the extent of its applications over organic chemistry, ${ }^{13}$ pharmaceutical chemistry, ${ }^{14}$ diagnoses, ${ }^{15}$ materials,${ }^{16}$ and polymer science. ${ }^{17,18}$

Concerning triazoles, Huisgen ${ }^{19}$ was the first to perform the 1,3-dipolar cycloaddition of azides with terminal alkynes to form disubstituted 1,2,3-triazoles. Huisgen cycloaddition produces the mixture between the 1,4 and 1,5-disubstituted products. This reaction is carried out by heating $\left(60-120{ }^{\circ} \mathrm{C}\right)$ and can take hours or days. In 2002, Sharpless and co-workers ${ }^{20}$ reported the 1,3-dipolar $\mathrm{CuAAC}$ reaction, which is completely regioselective for the formation of 1,4-disubstituted triazoles. In this case the reaction is carried out at room temperature and has high conversions at shorter times, compared to the uncatalyzed cycloaddition reported by Huisgen. ${ }^{19}$ For this reason the complex CuAAC became the most known click reaction. ${ }^{20}$ 
Other strategies have been reported ${ }^{21-24}$ to perform the cycloaddition of alkynes and azides without the use of a copper catalyst; however, for these reactions, the kinetics is slow and does not present regioselectivity. Due to these facts, for cycloaddition reactions, copper salts seem to be the better option.

It is important to note that organic electrosynthesis is an excellent alternative since it has a history of more than 200 years of development and has produced a very extensive literature. Electrolysis remains a very little used procedure for the synthesis of organic compounds in both academic and industrial processes. ${ }^{25}$ We have previously reported assisted synthesis by electrolysis to improve the synthesis of mono and disubstituted benzimidazoles, ${ }^{26}$ hydantoins, ${ }^{27}$ and recent chalcones. Analyzing the mechanism of click reactions and looking for an innovative faster procedure to synthesize triazoles, this paper proposes to assist a conventional click reaction by electrochemical methods. Since a metallic species as $\mathrm{Cu}^{0}$ may be relatively easy to oxidize by electrolysis, the main objective is to generate ionic species of $\mathrm{Cu}^{0}$ as $\mathrm{Cu}^{\mathrm{I}}$ serving to catalyze the triazole click reaction. For this purpose, a suitable electrolytic media, as well as a proper electrochemical cell configuration, were used, first to establish the electrolysis electrode potential and then to test the reaction improvement by the in situ electrooxidation of $\mathrm{Cu}^{0}$, considering the electrons as redox reactants instead of polluting reducing/oxidizing reagents. ${ }^{28}$ It is also important to consider that electric current is equivalent to the velocity of the formation of $\mathrm{Cu}^{\mathrm{I}}$.

\section{Experimental}

\section{General procedures}

All common reagents were obtained from Aldrich (Saint Louis, Missouri, USA) and used without further purification. The synthesized compounds were detected by thin-layer chromatography (TLC) performed on silica gel $\mathrm{F}_{254}$ plates (Merck) using UV light. Infrared spectra (IR) were recorded on a PerkinElmer FT-IR 1600 spectrophotometer. ${ }^{1} \mathrm{H}$ and ${ }^{13} \mathrm{C}$ nuclear magnetic resonance (NMR) spectra at 200 and $50 \mathrm{MHz}$, respectively, were recorded on a Varian Mercury $200 \mathrm{MHz}$ Spectrometer at $300 \mathrm{~K}$ using $5 \mathrm{~mm}$ sample tubes in $\mathrm{CDCl}_{3}$ and/or dimethyl sulfoxide (DMSO- $d_{6}$ ) with tetramethylsilane (TMS) as the internal standard. Mass spectra (MS) were obtained on an Agilent Technologies 5975C MS Spectrometer at $70 \mathrm{eV}$ by direct insertion. The morphology and the surface elemental composition were determined by field emission scanning electronic microscopy (FESEM) in a JEOL 7800F Prime.
The energy dispersive spectroscopy (EDS) was determined in a Bruker QUANTAX 200.

\section{Conventional method for click reaction}

In a vial, it was placed benzyl bromide $(144 \mathrm{mg}$, $0.84 \mathrm{mmol}$ ), sodium azide $(60 \mathrm{mg}, 0.92 \mathrm{mmol})$, the catalyst, $\mathrm{CuSO}_{4}(10.5 \mathrm{mg}, 0.042 \mathrm{mmol})$, sodium ascorbate $(25 \mathrm{mg}, 0.126 \mathrm{mmol})$ and phenylacetylene $(86 \mathrm{mg}$, $0.84 \mathrm{mmol})$ in tert-butyl alcohol/water $(1: 1)(4 \mathrm{~mL})$. The vial was capped and placed into hard stirring for $60 \mathrm{~min}$. The reaction was followed by TLC and finally filtered with ethyl acetate $(40 \mathrm{~mL})$ in silica and a thin layer of celite..$^{29}$ The excess of solvent was eliminated at reduced pressure and the solid obtained was characterized by NMR, MS and IR.

\section{Electrochemical method for click reaction}

Tetrabutylammonium tetrafluoroborate (TBATFB) salt (equivalent $0.0001 \mathrm{~mol}$ ) was placed in a $200.0 \mathrm{~mL}$ beaker with $40 \mathrm{~mL}$ of tert-butyl alcohol/water (1:1) to dissolve, the mixture was kept under stirring for 2 min with a magnetic stirrer to dissolve the solid, after that, it was placed in a volumetric flask $(50 \mathrm{~mL})$ to complete the volume with tert-butyl alcohol/water (1:1). This salt was an analytical reagent from Merck (Mexico city, Mexico). It is important to mention that TBATFB was selected as a supporting electrolyte because it is soluble in the reaction medium: tert-butyl alcohol/water (1:1). Moreover, tert-butyl alcohol and tetrabutylammonium have similar structures, making them compatible and miscible, accomplishing the requirements of a supporting electrolyte.

\section{Electrochemical oxidation of metallic $\mathrm{Cu}$ foil}

The supporting electrolyte $(4 \mathrm{~mL})$ was placed in a $20.0 \mathrm{~mL}$ undivided electrochemical cell. A typical three-electrode system was used, high purity $\mathrm{Cu}^{0}$ foil $\left(0.25 \mathrm{~cm}^{2}\right.$ area) was used as a working electrode (WE), Pt coil was used as a counter electrode (CE), and $\mathrm{Ag} / \mathrm{AgCl}$ rod immersed in saturated $\mathrm{KCl} /$ tert-butyl alcohol/ water (1:1) solution as a reference electrode. Anodic linear sweep voltammetry was performed to the bare copper foil serving as a working electrode in the supporting electrolyte to select its suitable electrooxidation potential. This electrode potential will be used during the forthcoming triazoles electrochemical synthesis. The experiment was made with a potentiostat-galvanostat from BASI using Epsilon software. $\mathrm{Cu}^{0}$ oxidation onset was identified at $0.30 \mathrm{~V}$ vs. $\mathrm{Ag} / \mathrm{AgCl} / \mathrm{Cl}^{-}{ }_{\text {(tert-butyl alcohol/water) }}{ }^{30}$ 


\section{Electrochemical synthesis of triazoles}

In the electrochemical cell of $20.0 \mathrm{~mL}$ the supporting electrolyte was placed $(4.0 \mathrm{~mL})$ as well as electrodes $\left(\mathrm{Cu}^{0}\right.$ (working electrode), $\mathrm{Ag} / \mathrm{AgCl} / \mathrm{Cl}^{-}{ }_{\text {sat } \mathrm{KCl} \text { (tert-butyl alcohol/water) }}$ (reference electrode) and $\mathrm{Pt}$ (counter electrode)), then the reaction reagents were added; benzyl bromide (144 mg, $0.84 \mathrm{mmol})$, sodium azide $(60 \mathrm{mg}, 0.92 \mathrm{mmol})$ and phenylacetylene $(86 \mathrm{mg}, 0.84 \mathrm{mmol})$. For a first experimental series, a constant voltage of $0.3 \mathrm{~V} v s$. $\mathrm{Ag} / \mathrm{AgCl} / \mathrm{Cl}^{-}{ }_{\text {sat } \mathrm{KCl} \text { (tert-butyl alcohol/water) }}$ was applied to the working electrode, in the second series a pulse voltage was selected to ensure $\mathrm{Cu}^{0}$ electrooxidation following a rest time without polarization to allow a relaxation of the interface. Both cases were done using the Autolab potentiostat-galvanostat and stirring constantly for $60 \mathrm{~min}$. Figure 1 shows the pulsed potential program, composed by 40 cycles between oxidation at $0.3 \mathrm{~V} v s$. $\mathrm{Ag} / \mathrm{AgCl} /$ $\mathrm{Cl}^{-}{ }_{\text {sat KCl (tert-butyl alcohol/water) }}$ for $60 \mathrm{~s}$ and rest potential at $-1 \mathrm{~V} v s$. $\mathrm{Ag} / \mathrm{AgCl} / \mathrm{Cl}^{-}{ }_{\text {sat KCl (tert-butyl alcohol/water) }}$ for $30 \mathrm{~s}$. The reaction was monitored by TLC.

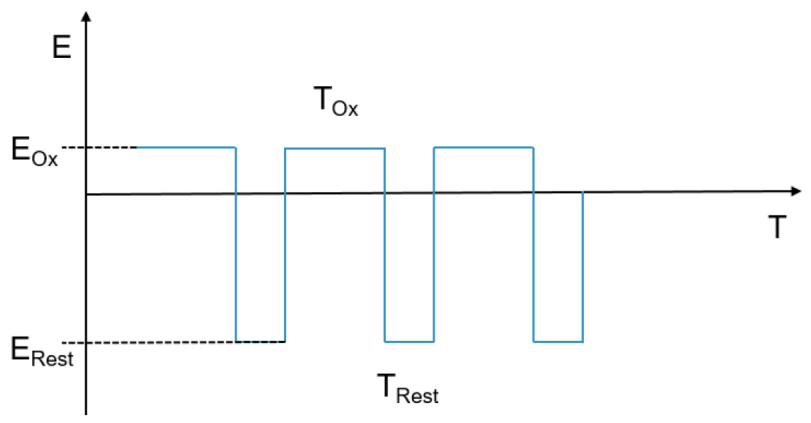

Figure 1. Pulsed potential program for the electrochemical process.

\section{Results and Discussion}

In this paper, three types of experiments are reported: first, a modified click chemistry protocol (Scheme 1a); second, the continuous oxidation of the copper foil electrode; and third, the pulsed oxidation of copper foil electrode, the last two to generate the $\mathrm{Cu}^{\mathrm{I}}$ ion that is responsible for the catalysis in the click chemistry (Scheme 1b).

The click chemistry reaction was carried out with benzyl bromide, sodium azide, and phenylacetylene as a starting material, using the base reaction shown in Scheme 1a, consisting of the addition of benzyl bromide and sodium azide to produce benzyl azide (this reaction is carried out in 5 min). Later on, copper sulfate and sodium ascorbate were added followed by phenylacetylene. ${ }^{21-24}$ This reaction was carried out using $5 \mathrm{~mol}_{\%} \mathrm{CuSO}_{4}$ and $15 \mathrm{~mol} \%$ sodium ascorbate as the source of the $\mathrm{Cu}^{\mathrm{I}}$ catalyst required for the formation of the triazole.

\section{Electrochemical $\mathrm{Cu}^{0}$ oxidation}

$\mathrm{Cu}^{0}$ electrooxidation may form $\mathrm{Cu}^{\mathrm{I}}$ and/or $\mathrm{Cu}^{\mathrm{II}}$ species in an aqueous medium as mentioned in several reports; ${ }^{31-34}$ then the expectation was that pure $\mathrm{Cu}^{0}$ foil in TBATFB/ tert-butyl alcohol/water would form $\mathrm{Cu}^{\mathrm{I}}$, considering that electrode potential and solution conditions allow this process as Hernandez et al..$^{35}$ proposed the formation of $\mathrm{Cu}^{\mathrm{I}}$ species controlling electrode potential and solution chemistry. This fact was demonstrated by the formation of triazoles using $\mathrm{Cu}^{0}$ electrooxidation as the source of catalyst used in click reaction. ${ }^{10}$

To offset the influence of the electrolytic medium on the voltammetric response, the copper foil was submerged in the supporting electrolyte to determine its electrooxidation onset potential in $2 \mathrm{mM}$ TBATFB dissolved in tert-butyl alcohol/water (1:1), serving as a supporting electrolyte without reagents. Cyclic voltammetry showed in Figure 2 allowed to determine that $0.3 \mathrm{~V} v s . \mathrm{Ag} / \mathrm{AgCl} / \mathrm{Cl}^{-}{ }_{\text {sat KCl}}$ is the onset potential for $\mathrm{Cu}^{0}$ electro-dissolution in the triazole reaction medium, which is more positive compared with the thermodynamic value of $\mathrm{Cu}^{0}$ to $\mathrm{Cu}^{\mathrm{II}}$ electrooxidation in aqueous media $\left(0.12 \mathrm{~V} v s . \mathrm{Ag} / \mathrm{AgCl} / \mathrm{Cl}^{-}{ }_{\text {sat KCl}}\right)$ and the same as that of $\mathrm{Cu}^{0}$ to $\mathrm{Cu}^{\mathrm{I}},{ }^{36}$ confirming the $\mathrm{Cu}^{\mathrm{I}}$ formation on the electrode surface. For the organic-electro-assistedsynthesis (OEAS) of triazoles a constant potential of $0.3 \mathrm{~V}$ vs. $\mathrm{Ag} / \mathrm{AgCl} / \mathrm{Cl}^{-}{ }_{\text {sat KCl }}$ is going to be used, assuming

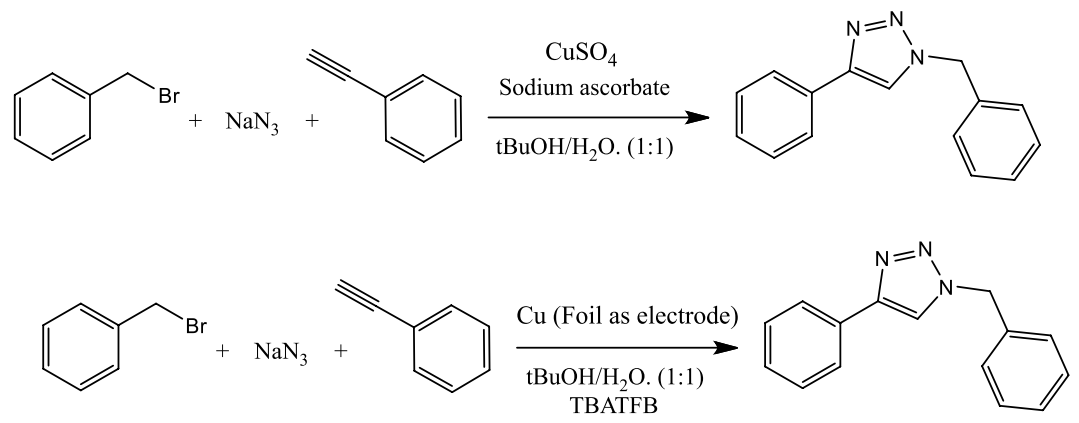

Scheme 1. Synthesis of triazole by the reaction of click: (a) conventional and (b) electrochemical methods. 
that $\mathrm{Cu}^{0}$ electrooxidation will also be very slow at this electrode potential. ${ }^{37}$

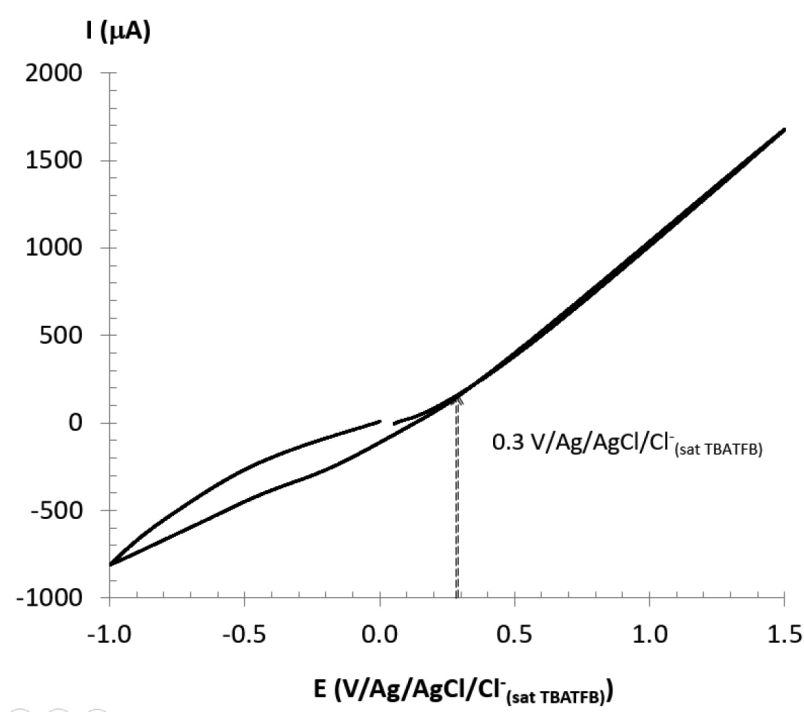

Figure 2. Cyclic voltammetry of the $\mathrm{Cu}^{0}$ foil in TBATFB dissolved in tert-butyl alcohol/water (1:1) as supporting electrolyte.

In Figure 3, the triazole electrochemical assisted synthesis was registered in a current-time plot, representing the bulk electrolysis in the undivided three-electrode cell, using a working electrode $\mathrm{Cu}^{0}$ of high purity to produce a solid-state catalyst for triazole synthesis, in tert-butyl alcohol/water (1:1) at room temperature. For the three triazoles (see Table 1), the plot shows a similar fall of the current in the cell, suggesting surface passivation after the first seconds of reaction. However, when reviewing the graph in Figure 3 in detail, it is noted that triazole 3 has a greater drop in current than those of $\mathbf{2}$ and $\mathbf{1}$, which is a determining factor and the current is inversely proportional to the yield. Surface passivation is mainly an effect produced by triazole. ${ }^{38}$ These compounds are well known for their action as metallic corrosion inhibitors. ${ }^{38}$

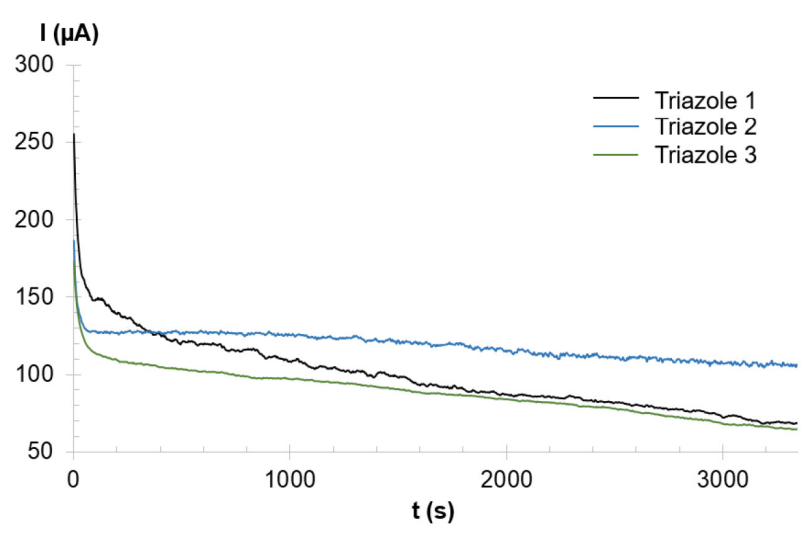

Figure 3. Bulk electrolysis to synthesize the triazole showed in Table 1 assisted by $\mathrm{Cu}$ electro-oxidation at a constant voltage $0.3 \mathrm{~V} v s$. $\mathrm{Ag} / \mathrm{AgCl} /$ $\mathrm{Cl}_{\text {sat KCl(tert-butyl alcohol/water). }}^{-}$

\section{Conventional vs. electrochemical method}

Table 1 presents the reaction yields and reagent types for the two methods. It is important to notice that in both procedures, the reaction yields followed the same trend, i.e., the yields are better by the electrochemical method as shown in the three reactions $(\mathbf{1}, \mathbf{2}$ and $\mathbf{3})$. These results indicate that the formation of $\mathrm{Cu}^{\mathrm{I}}$ on the surface of the $\mathrm{Cu}$ foil was very efficient. This result suggests that the formation of $\mathrm{Cu}^{\mathrm{I}}$ is greater on the surface of the $\mathrm{Cu}^{0}$ foil

Table 1. Comparison between the conventional method and the electrochemical method

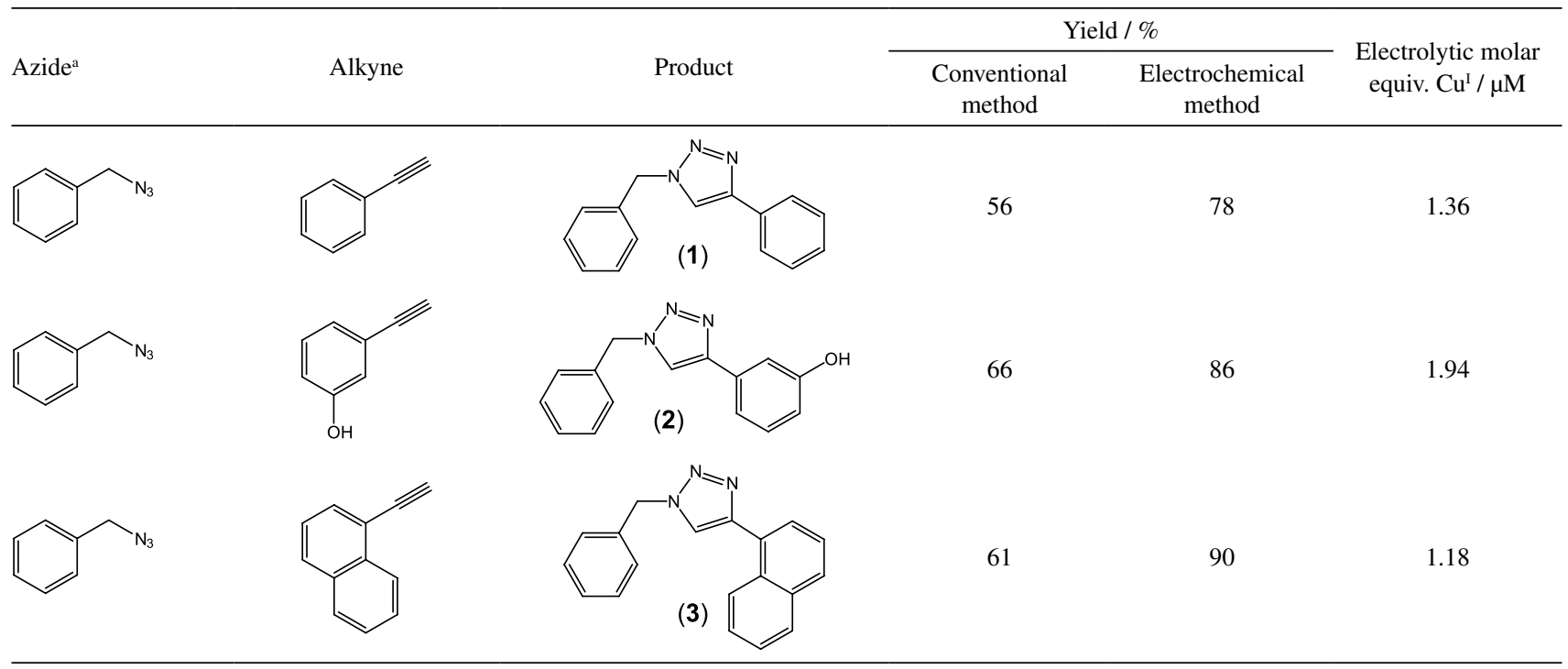

${ }^{\mathrm{a} B e n z y l}$ azide was prepared in situ. 
and the reaction speed increases. It was also notable that no additional purification step is required to obtain the final product in the electrochemical method.

For triazole the plot suggests surface passivation after $8 \mathrm{~min}$ approximately; however, the reaction yield (Table 1) indicates $78-90 \%$. Surface passivation is mainly an effect produced by triazole. These compounds are well known for their action as metallic corrosion inhibitors. Even though, the yield was remarkably enhanced with in situ $\mathrm{Cu}^{0}$ electrooxidation compared with that using $\mathrm{CuSO}_{4}$-sodium ascorbate as a catalyst. It was demonstrated that the electrochemical process is more efficient and faster.

During the study, the copper foil appeared to dissolve slowly in the reaction solution and turned blue which intensified as the reaction developed. This was a clear indication of the formation of $\mathrm{Cu}^{\mathrm{I}} \cdot{ }^{39}$ After the study, small holes can be seen on the surface of the working electrode.

For triazole 1, the general method of synthesis shows $56 \%$ of yield at $60 \mathrm{~min}$; for the same time, the electrochemical method shows $78 \%$ of yield, which represents a $22 \%$ increase in the synthetic performance. For triazole 2, the electrochemical methods gave us a yield of $86 \%$, an increase of $20 \%$ compared with the yield obtained with the general method (66\%). For triazole 3, the general method shows a modest yield of $61 \%$, which was highly improved by the electrochemical method by almost $30 \%$, showing a $90 \%$ of the reaction yield in one hour. As can be seen for the three different triazoles, the electrochemical method shows increases of more than $20 \%$ in the reaction yield at the same time and under the same conditions of stirring and temperature as the general method.

\section{Surface study and elemental analysis by FESEM}

The morphology study of the copper foil, before and after the OEAS, was done by FESEM and EDS elemental analysis. Both samples were analyzed without any previous preparation. Figure 4 shows FESEM images and allows us to describe the effect of electrochemical $\mathrm{Cu}^{0}$ oxidation on the metallic foil. Figure $4 \mathrm{c}$ shows the mapping of the image by the EDS detector and shows the elemental distribution on the copper foil and, in Figure 4d, after the electrosynthesis (constant imposed potential of $0.3 \mathrm{~V}$ vs. $\left.\mathrm{Ag} / \mathrm{AgCl} / \mathrm{Cl}^{-}{ }_{\left(\mathrm{BuOH}: \mathrm{H}_{2} \mathrm{O}\right)}\right)$, it is shown that a new species has been formed on the copper foil.

Table 2 shows copper foil EDS analysis before and after the induced electrolytic process. This result indicates that a new copper phase has been formed and through the postulate of the mechanism is proposed to be the $\mathrm{Cu}_{2} \mathrm{O}$. This

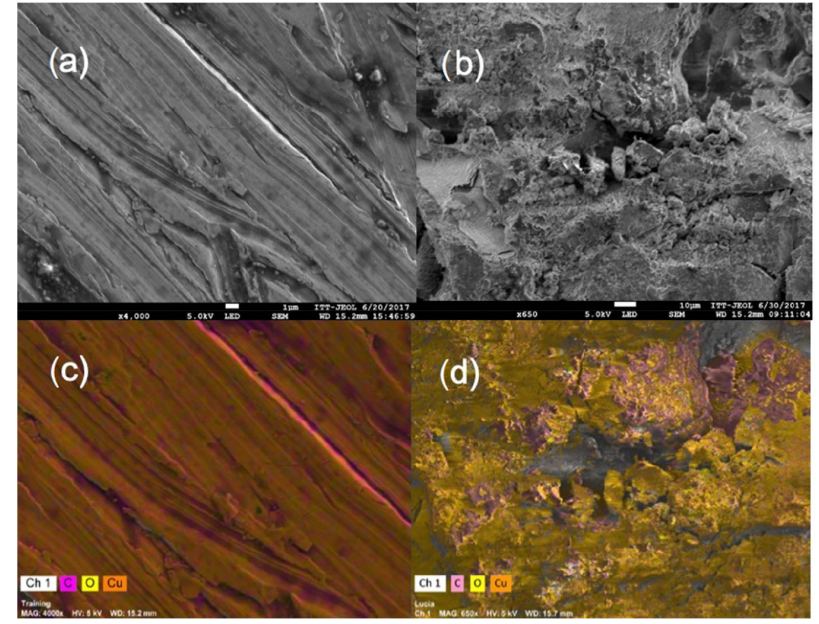

Figure 4. FESEM image of $\mathrm{Cu}^{0}$ foil: (a) before electrolysis; (b) after electrolysis; (c) EDS elemental analysis map, before electrolysis; (d) EDS elemental analysis map, after electrolysis.

Table 2. Elemental analysis from EDS of $\mathrm{Cu}^{0}$ electrode, before and after the electrochemical assisted synthetic process

\begin{tabular}{lcc}
\hline Element & $\begin{array}{c}\text { Before electrochemical } \\
\text { oxidation / at.\% }\end{array}$ & $\begin{array}{c}\text { After electrochemical } \\
\text { oxidation / at.\% }\end{array}$ \\
\hline $\mathrm{Cu}$ & 95.04 & 63.32 \\
$\mathrm{C}$ & 3.02 & 16.23 \\
$\mathrm{O}$ & 1.36 & 10.08 \\
Other & 0.58 & 10.37 \\
\hline
\end{tabular}

fact can be supported by a recent publication ${ }^{40}$ reporting that $\mathrm{Cu}_{2} \mathrm{O}$ is a suitable crystalline solid formed by the electrochemical deposition of metallic $\mathrm{Cu}^{0}$.

After visualizing the effect of $\mathrm{Cu}^{0}$ electrooxidation and the decay of current density after $8 \mathrm{~min}$, the hypothesis of passivation was proved. To compensate for this passive film formation, we suggested an OEAS with pulsed potential signals applied to the $\mathrm{Cu}^{0}$ foil expecting to recover its catalytic activity (constant anodic current density) by a periodic oxidation potential.

\section{Electrochemical pulsed technique}

Table 3 compares the yields obtained in the conventional method against those obtained in the pulse method. The pulsed program improves by $36 \%$ the performance of the conventional click reaction for triazole $\mathbf{1}$, under the same conditions of time, agitation, and temperature, giving a yield of $92 \%$ in one hour of reaction.

Figures 3 and 5 show the tendency of the current versus time. In the constant potential program (Figure 3), the catalyst is formed throughout the reaction time, but progressively in smaller quantity, since the current decreases noticeably due to the passivation of the surface. On the contrary, in the pulsed potential program 
Table 3. Comparison between the conventional method and the electrochemical pulsed method

Azide

(Figure 5), during the first $25 \mathrm{~min}$ of the reaction, the current remains constant at $100 \mu \mathrm{A}$. Using Faraday's law, it can be calculated that $65 \%$ of the total catalyst has been generated in $25 \mathrm{~min}$ at a constant potential. For the pulsed potential method at the same time, it is formed only $56 \%$ of the catalyst; however, a higher yield is obtained. The pulsed method gives us a more efficient way to synthesize triazoles, with higher yields in $60 \mathrm{~min}$ and with a lower amount of copper $(\mu \mathrm{g})$. Therefore, the good selection of an electrochemical method is very important in the synthesis of triazoles because the reaction proceeds in small amounts of $\mathrm{Cu}^{\mathrm{I}}$ ion. This is essential since the $\mathrm{Cu}^{\mathrm{I}}$ ion residues will be eliminated and allow synthesized triazoles to be used in a wide variety of biological applications with more security.

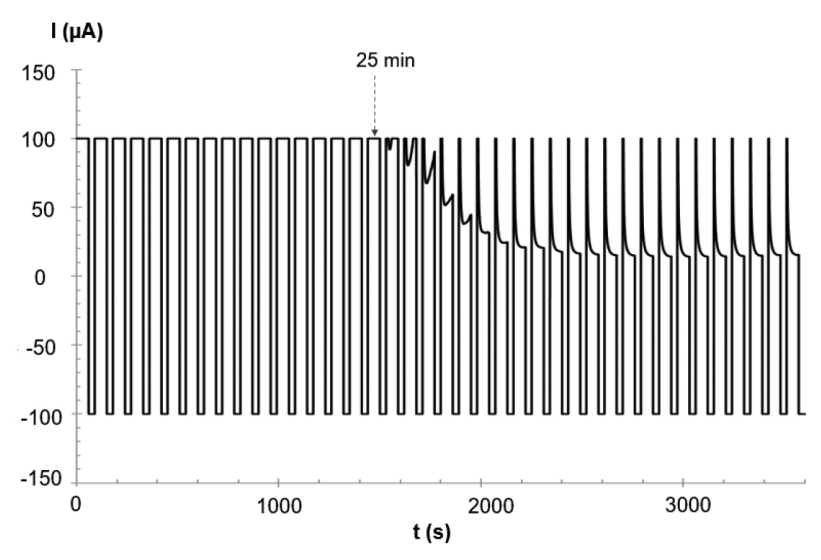

Figure 5. Pulse $\mathrm{Cu}^{0}$ electrooxidation.

Integrating the current-time plots and using Faraday's law, it was possible to calculate the number of $\mathrm{Cu}^{\mathrm{I}}$ moles produced as a catalyst. An estimation of the amount of copper generated to catalyze the reaction in the continuous potential program was ca. $1.5 \mu \mathrm{mol}$ (average of the three triazoles) in one hour (Table 1), and for the pulsed potential program was $0.77 \mu \mathrm{mol}$ (triazole 1, Table 3 ), that is 10 and ca. 19.5 times less than the amount used in the classical click method, respectively. The efficiency of the method is due to the controlled production of $\mathrm{Cu}^{\mathrm{I}}$ by soft electrochemical oxidation conditions.
Mechanism for click reaction ${ }^{4-43}$

Encouraging results have been obtained from the click reaction assisted by the electrochemical method. This result requires the postulation of the processes that are carried out during the electro-synthesis reaction (Scheme 2). It begins with the oxidation process on the copper foil which is the working electrode (step 1). The formation of $\mathrm{Cu}^{\mathrm{I}}$ cation, in basic condition, can form $\mathrm{Cu}_{2} \mathrm{O}$ (step 2). The formation of the $\mathrm{Cu}^{\mathrm{I}}$ cation acts as Lewis acid and reacts with the alkyne reagent to get an addition and asymmetrical pyramidal complex (step 3). The pyramidal complex undergoes a rearrangement to form the salt of the copper alkyne (step 4). This salt reacts with the azide to get the triazole product (step 5). Finally, $\mathrm{Cu}^{\mathrm{I}}$ can be reduced to $\mathrm{Cu}^{0}$ (step 6). The $\mathrm{Cu}^{\mathrm{I}}$ acts as a catalytic Lewis acid cation because a small amount is sufficient to produce the reaction, and this is reused in a cyclic process until the $\mathrm{Cu}^{\mathrm{I}}$ stabilizes as $\mathrm{Cu}_{2} \mathrm{O}$.

Therefore, if the reaction of the cyclic process is very efficient, a very small amount of $\mathrm{Cu}^{\mathrm{I}}$ is required and therefore $\mathrm{Cu}_{2} \mathrm{O}$ formation will be minimal, as demonstrated by the FESEM analysis.

\section{Conclusions}

Two electrochemical methods were developed for the reaction of the click chemistry, obtaining three different triazoles. The use of a copper foil as the working electrode was determinant for the reaction. The organic salt of TBATFB was used as an electrolyte to induce smooth oxidation of copper. The oxidation of copper foil produces $\mathrm{Cu}^{\mathrm{I}}$ which is responsible for the activation of the acetylene, forming the salt of the (phenylethynyl)copper which in turn is the reagent that condenses with the azide forming the triazole. The synthesis of 1-benzyl-4-phenyl-1H-1,2,3-triazole, 3-(1-benzyl-1H-1,2,3-triazol-4-yl)phenol and 1-benzyl4-(naphthalen-1-yl)-1H-1,2,3-triazole derivatives via the in situ preparation of $\mathrm{Cu}^{\mathrm{I}}$ by an electrochemical process was very efficient, safe, and inexpensive since catalyst was obtained under soft conditions reaction 


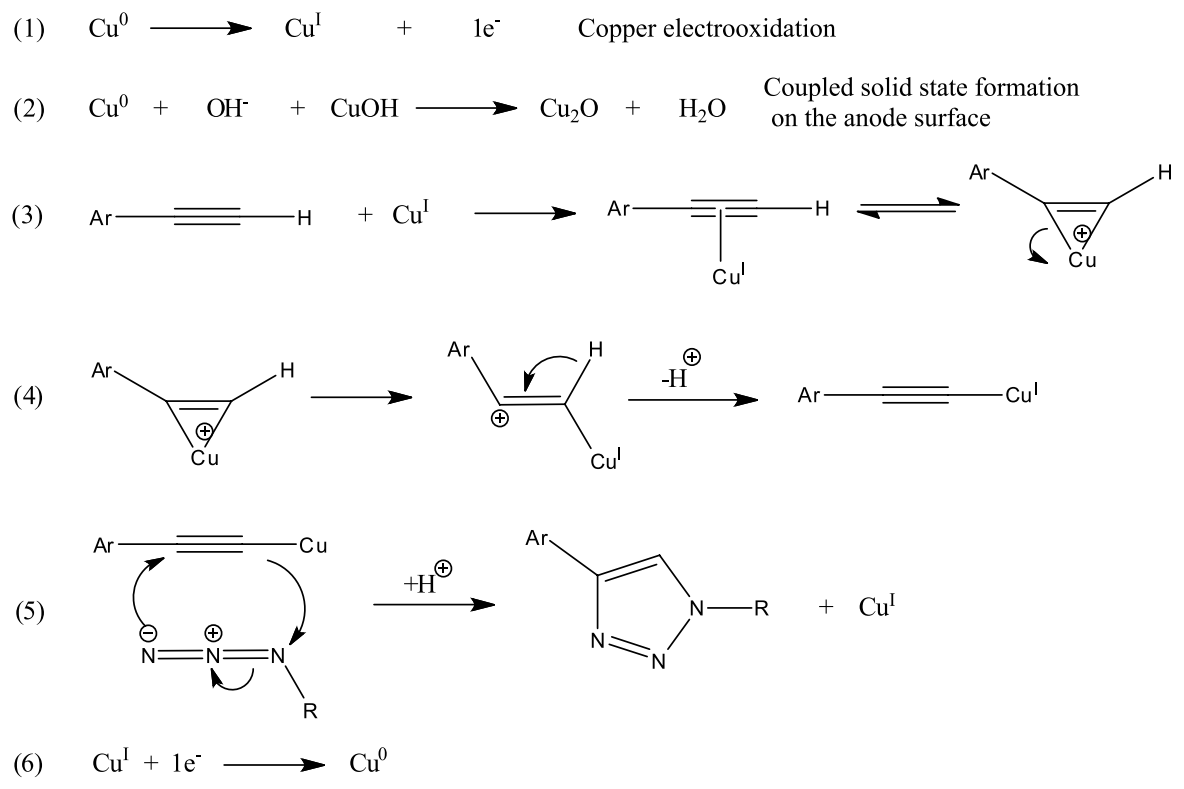

Scheme 2. Proposed mechanism for click reaction.

generating extremely small amounts of electrooxidized $\mathrm{Cu}$ (ca. $1.5 \mu \mathrm{mol}$ in one hour). The analysis of the copper foil by FESEM shows images describing the formation of copper species corresponding to $\mathrm{Cu}_{2} \mathrm{O}$ formed after the electrochemical oxidation process. It was possible to implement a program of potential in pulses in which it avoided the passivation of the surface of the metallic copper foil. The amount of copper that is required to activate the click reaction is in the ppm range, therefore it is a very controlled process that will not produce excessive pollution, it is a remarkable faster reaction and the $\mathrm{Cu}_{2} \mathrm{O}$ formed is feasible in the same process to achieve the reduction of copper, recovering it as $\mathrm{Cu}^{0}$. Conventional and electrochemical methods were compared, the last one yielded $78-90 \%$ in one hour and the conventional method produced only $35 \%$ at the same time. The electro-click is faster and more efficient by the assisted electrochemical method and pulse potential. This procedure can be adapted to the coupling of biological species.

\section{Supplementary Information}

Supplementary data (FTIR and NMR spectra) are available free of charge at http://jbcs.sbq.org.br as a PDF file.

\section{Acknowledgments}

Authors gratefully acknowledge support for this project by Consejo Nacional de Ciencia y Tecnología (CONACyT, grant No. 242823 and No. 269551) and graduate scholarship (No. 583636). They also acknowledge
Tecnológico Nacional de México for supporting this project (Clave 6823.18-P and 7814.20-P).

\section{References}

1. Bharathi, M. V.; Chhabra, M.; Paira, P.; Bioorg. Med. Chem. Lett. 2015, 25, 5737.

2. Baccile, J. A.; Morrell, M. A.; Falotico, R. M.; Milliken, B. T.; Drew, D. L.; Rossi, F. M.; Tetrahedron Lett. 2012, 53, 1933.

3. Morita, S.; Takasu, A.; Polymer 2018, 136, 194.

4. Barbosa, M.; Vale, N.; Costa, F. M. T. A.; Martins, M. C. L.; Gomes, P.; Carbohydr. Polym. 2017, 165, 384.

5. Kolb, H. C.; Finn, M. G.; Sharpless, K. B.; Angew. Chem., Int. Ed. 2001, 40, 2004.

6. Liu, X.; Qin, B.; Xu, J.-F.; Wang, Z.; Zhang, X.; J. Photochem. Photobiol., A 2018, 355, 414.

7. Warad, I.; Abdoh, M.; Al Ali, A.; Shivalingegowda, N.; Kumara, K.; Zarrouk, A.; Lokanath, N. K.; J. Mol. Struct. 2018, 1154, 619.

8. Zhou, W.; Zhang, H.; Chen, F.; Int. J. Biol. Macromol. 2018, 107, 790 .

9. Ye, R.; Faucher, F. F.; Somorjai, G. A.; Mol. Catal. 2018, 447, 65.

10. Liang, L.; Astruc, D.; Coord. Chem. Rev. 2011, 255, 2933.

11. Tale, R. H.; Gopula, V. B.; Toradma, G. K.; Tetrahedron Lett. 2015, 56, 5864.

12. Alonso, F.; Moglie, Y.; Radivoy, G.; Yus, M.; Tetrahedron Lett. 2009, 50, 2358.

13. Rossy, C.; Majimel, J.; Delapierre, M. T.; Fouquet, E.; Felpin, F.-X.; J. Organomet. Chem. 2014, 755, 78.

14. Whiting, M.; Muldoon, J.; Lin, Y.-C.; Silverman, S. M.; Lindstrom, W.; Olson, A. J.; Kolb, H. C.; Finn, M. G.; Sharpless, 
K. B.; Elder, J. H.; Fokin, V. V.; Angew. Chem., Int. Ed. 2006, 45, 1435.

15. Yoon, H. Y.; Koo, H.; Kim, K.; Kwon, I. C.; Biomaterials 2017, 132, 28.

16. Um, J.-E.; Song, S. G.; Yoo, P. J.; Song, C.; Kim, W.-J.; Appl. Surf. Sci. 2018, 429, 278.

17. Han, Y.; Yuan, L.; Li, G.; Huang, L.; Qin, T.; Chu, F.; Tang, C.; Polymer 2016, 83, 92.

18. Guo, J.-W.; Lin, Z.-Y.; Chang, C.-J.; Lu, C.-H.; Chen, J.-K.; Appl. Surf. Sci. 2018, 439, 313.

19. Huisgen, R.; Angew. Chem. 1963, 75, 604.

20. Rostovtsev, V. V.; Green, L. G.; Fokin, V. V.; Sharpless, K. B.; Angew. Chem., Int. Ed. 2002, 41, 2596.

21. Lee, S. Y.; Lee, S.; Lee, J.; Yhee, J. Y.; Yoon, H. I.; Park, S.-J.; Koo, H.; Moon, S.-H.; Lee, H.; Cho, Y. W.; Kang, S. W.; Lee, S.-Y.; Kim, K.; Biochem. Biophys. Res. Commun. 2016, 479, 779.

22. Blenke, E. O.; Klaasse, G.; Merten, H.; Plückthun, A.; Mastrobattista, E.; Martin, N. I.; J. Controlled Release 2015, 202, 14.

23. Chatkewitz, L. E.; Halonski, J. F.; Padilla, M. S.; Young, D. D.; Bioorg. Med. Chem. Lett. 2018, $28,81$.

24. Kosman, J.; Stanislawska, A.; Gluszynska, A.; Juskowiak, B.; Int. J. Biol. Macromol. 2017, 101, 799.

25. Pletcher, D.; Electrochem. Commun. 2018, 88, 1.

26. Santiago-Ruiz, S.; Torres-Pacheco, L. J.; Oropeza-Guzmán, M. T.; Rivero, I. A.; Int. J. Electrochem. Sci. 2016, 11, 6324.

27. Monreal, I.; Torres Pacheco, L. J.; Oropeza Guzman, M. T.; Rivero, I. A.; Int. J. Electrochem. Sci. 2015, 10, 6743.

28. Frontana-Uribe, B. A.; Little, R. D.; Ibanez, J. G.; Palma, A. I.; Vasquez-Medrano, R.; Green Chem. 2010, 12, 2099.

29. Sarmiento-Sánchez, J. I.; Ochoa-Terán, A.; Rivero, I. A.; ARKIVOC 2011, ix, 177.
30. Eh, A. L.-S.; Lin, M.-F.; Cui, M.; Cai, G.; Lee, P. S.; J. Mater. Chem. C 2017, 5, 6547.

31. Heli, H.; Jafarian, M.; Mahjani, M. G.; Gobal, F.; Electrochim. Acta 2004, 49, 4999.

32. Jafarian, M.; Rashvand, A. M.; Danaee, I.; Gobal, F.; Mahjani, M. G.; Chin. J. Catal. 2010, 31, 1351.

33. Fineberg, D. J.; Haynes, R.; Jannett, F. J.; Rapp, W. E.; J. Appl. Electrochem. 1983, 13, 177.

34. Auer, A.; Andersen, M.; Wernig, E. M.; Hörmann, N. G.; Buller, N.; Reuter, K.; Kunze-Liebhäuser, J.; Nat. Catal. 2020, 3, 797.

35. Hernandez, R. M.; Aiken, L.; Baker, P. K.; Kalaji, M.; J. Electroanal. Chem. 2002, 520, 53.

36. Bard, A. J.; Parsons, R.; Jordan, J. In Standard Potentials in Aqueous Solution; Bard, A. J.; Parsons, R.; Jordan, J., eds.; Basel: New York, 1985, p. 293.

37. Bard, A. J.; Faulkner, L. R.; White, H. S.; Electrochemical Methods: Fundamentals and Applications; Wiley: New York, 1980, p. 637.

38. Faisal, M.; Saee, A.; Shahzad, D.; Abbas, N.; Larik, A. F.; Pervaiz, A. C.; Fattah, T. A.; Khan, D. M.; Shehzadi, S. A.; Corros. Rev. 2018, 36, 507.

39. Koffyberg, F. P.; Benko, F. A.; J. Appl. Phys. 1982, 53, 1173.

40. Liau, L. C.-K.; Tung, T.-Y.; Electrochim. Acta 2018, 282, 395.

41. Hänni, K. D.; Leigh, D. A.; Chem. Soc. Rev. 2010, 39, 1240.

42. Döhler, D.; Michael, P.; Wolfgang, H.; Binder, W. H.; Acc. Chem. Res. 2017, 50, 2610.

43. Chassaing, S.; Bénéteau, V.; Pale, P.; Catal. Sci. Technol. 2016, $6,923$.

Submitted: November 6, 2020

Published online: March 12, 2021 